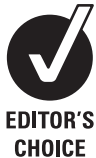

\title{
UK childhood exposures to pesticides 2004-2007: a TOXBASE toxicovigilance study
}

\author{
R D Adams, D Lupton, A M Good, D N Bateman
}

NPIS Edinburgh, Royal Infirmary of Edinburgh, Edinburgh,

Scotland, UK

\section{Correspondence to:}

Richard Adams, NPIS Edinburgh,

Royal Infirmary of Edinburgh, 51

Little France Crescent, Edinburgh

EH16 4SA, Scotland, UK;

richard.d.adams@luht.scot.nhs. uk

Accepted 3 December 2008 Published Online First

6 January 2009

\section{ABSTRACT}

Objective: There are no systematic methods for toxicovigilance of non-medicinal products in the UK. This is particularly relevant for pesticides, where there is significant public concern about potential adverse effects. This study describes a prospective toxicovigilance scheme based on follow-up of enquiries to the National Poisons Information Service (NPIS) through its online poisons information system TOXBASE. These enquiries reflect acute exposures and the patterns of acute illness that result.

Results: A total of 10061 pesticide-related enquiries were identified. After follow-up, data were gathered on 2364 suspected exposures, of which 1162 involved children. After exclusions, 1147 exposures are reported here. No deaths were reported and only 37 children were admitted to hospital. The majority were considered to have either minimal or no features $(925,80.6 \%)$. Symptoms for 38 children were unknown. Symptoms reported in the other 184 children included nausea or vomiting (58), eye irritation, pain or conjunctivitis (29), skin irritation (28), abdominal pain (24), mouth or throat irritation (18) and diarrhoea (15). Where age was recorded, $60.5 \%$ (680) of children involved in suspected pesticide exposures were aged 2 years or less. The most common scenario for acute accidental exposure to pesticide in children was exposure after application (329, $28.7 \%)$ or due to poor storage $(228,19.9 \%)$.

Conclusions: Areas of potential concern identified included storage, access of young children to "laid" baits and pesticides, and exposures as a result of medication errors, with liquid head lice preparations being confused with other medicines. Use of NPIS systems provides a potentially useful method of toxicovigilance.

There are at present no formal toxicovigilance structures in the UK for monitoring the effects of exposures to pesticides. These continue to cause anxiety among members of the public. ${ }^{1-4}$ Management of these cases presents a challenge to health professionals, particularly in childhood, where there is relatively little information on acute outcomes from these exposures. For most pesticides, acute effects reflect the extent of exposure. This information is of relevance to licensing, improved safety in use and advice on treatment.

We therefore conducted a longitudinal study, the first of this type reported in the UK, to examine the health effects of pesticide exposures using National Poisons Information Service (NPIS) systems. ${ }^{56}$ Here we report findings in exposures of children ( $\leqslant 12$ years old) to pesticides about which enquiries were made to TOXBASE between 1 April 2004 and 31 March 2007.

\section{What is already known on this topic}

- There is very little information on the nature and effects of acute pesticide exposures in children.

- Internationally, annual reports from the American Association of Poison Control Centers NPDS (National Poison Data System) and TESS (Toxic Exposure Surveillance System) have not looked specifically at this issue.

- In the UK, data on accidental pesticide exposures in children are currently limited.

\section{What this study adds}

- This first longitudinal study of its type to be performed in the UK provides information on the nature and range of exposures.

- It provides significant reassurance that pesticide products currently available do not present a generalised acute health hazard after accidental exposure.

- It also demonstrates that toxicovigilance studies such as this can gather potentially valuable exposure information.

\section{METHODS}

TOXBASE is the internet database of the NPIS. ${ }^{7}$ A list of pesticides of specific interest was agreed between the Pesticides Safety Directorate of the UK Health and Safety Executive and NPIS Edinburgh in 2004, and monographs for these pesticides were identified on TOXBASE. By March 2007, 324 TOXBASE entries for products and specific agents were being tracked. Users accessing these pesticides for a patient-related enquiry were requested to complete an online form. If they did not, a postal questionnaire based on that of Leverton and colleagues ${ }^{8}$ was sent, with a covering letter and prepaid return envelope. No postal questionnaires were sent to NHS Direct or NHS 24 , because of the difficulties of identifying case details in their systems. Responses about the same exposure were combined.

All telephone enquiries to NPIS Edinburgh (>90\% from Scotland) about pesticides received during the period were followed up. Thus the total number of questionnaires comes from three sources: electronic questionnaires, follow-up of TOXBASE users who did not complete an 


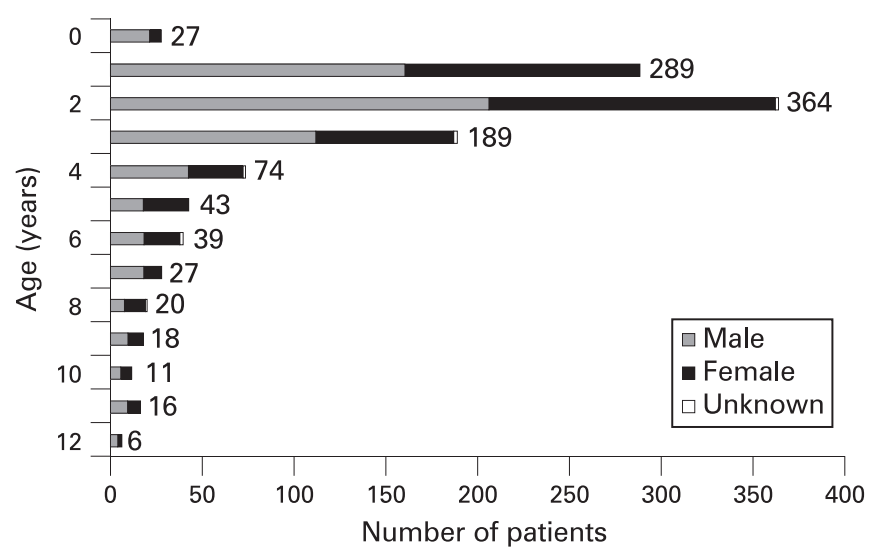

Figure 1 Age distribution of 1123 children involved in acute accidental exposures whose specific age was recorded.

electronic questionnaire and follow-up of telephone calls to NPIS Edinburgh.

The severity of acute poisoning in children was assessed in two ways. First, respondents were asked to grade the exposure ("not at all serious", "minor", "moderate", "major", "uncertain"). Second, experienced poisons information staff in Edinburgh used the poisoning severity score (PSS): ("fatal", 4; "severe", 3; "moderate", 2; "minor", 1; "none", 0; or "uncertain"), to grade the symptoms reported. ${ }^{9}$

\section{RESULTS}

Between 1 April 2004 and 31 March 2007, a total of 10061 patient-related pesticide enquiries were identified.

Data on 2364 patient exposures were subsequently gathered, of which 1162 concerned exposures of children. Nine children were excluded from the analysis because their symptoms were thought not to be related to the exposure (eg, timings of exposure and symptoms; other illness deemed responsible). Other reasons for exclusion were deliberate self-harm (1), exposures reported as chronic (3) and exposures where the nature of the putative exposure was not identified (2). Of the 1147 acute accidental exposures of children reported, $1123 \mathrm{had}$ a specific age recorded; 680 of these children were aged 2 years or less (fig 1). Only 295 (45.5\%) of 649 responders reported the patient as "definitely" exposed.

Overall, $56.6 \%$ (642) of the children were boys, as were $77.7 \%$ (21) of those $<1$ year old (fig 1). There was no gender difference in older children (table 1).

The vast majority of children (1106, 96.4\%) were not admitted to hospital or were discharged on the same day. Thirty-seven required admission for one day, 24 having no symptoms and 11 minor symptoms only. The severity of childhood exposures was considered "minor" or "not at all serious" by the responder in $76.1 \%$ (431) of 566 cases. PSS scores indicated low toxicity, with no cases graded PSS 3 or $4 ; 12$ graded PSS 2; 166, PSS 1; 925, PSS 0; and 44, "uncertain".
There were 403 (35.0\%) exposures involving insecticides: 215 pyrethroids (1 sheep dip), 18 organophosphorus insecticides (2 sheep dips), 52 carbamates and 119 others, of which 90 were boric acid. Among exposures to insecticide (239), 20.8\% involved ant killers. Other major categories were herbicides (110, 9.6\%), rodenticides $(259,22.5 \%)$, slug killers $(139,12.1 \%)$, head lice treatment $(178,15.5 \%)$, wood preservatives $(36,3.1 \%)$ and fungicides (8, 0.7\%).

The active ingredients most frequently identified in these exposures of children were permethrin (insecticide), malathion (head lice treatment) and metaldehyde (slug killer) (table 2). Most exposures (94.4\%) were to products for non-professional use in the home or garden.

The most common scenario for acute accidental exposure in children was that they were exposed as a consequence of use but not during application $(329,28.7 \%)$. These were often to bait-type products, or were due to unsatisfactory storage (228, $19.9 \%)$. Of the 329 cases where the exposure occurred after application, 119 (36.2\%) involved rodenticides; 96 (29.2\%), ant killers; and $53(16.1 \%)$, slug killers. The most frequent route of exposure was ingestion (778, 69.1\%). Multiple routes of exposure were found for $17.9 \%$ (201) of children.

Symptoms were absent in 925 (80.6\%); for 38 the question was answered "unknown" or was not recorded; in the 184 children who had symptoms, these included nausea or vomiting (58), eye irritation (29), skin irritation (28), abdominal pain (24), mouth or throat irritation (18) and diarrhoea (15).

Of exposure to head lice treatments, therapeutic error accounted for 29 (16.3\%) of 178, these products being mistaken for an oral medication (41.4\% for paracetamol). Seven $(24.1 \%)$ patients exposed because of therapeutic error had symptoms, similar to the prevalence of symptoms in head lice exposures overall (43, or $24.4 \%)$.

Of 259 patients exposed to rodenticides, 44 respondents recorded measuring the INR (international normalised ratio) or prothrombin time, although most (26) did not report the result. Of the 18 who did record the outcome, 16 found normal and only two prolonged prothrombin time.

Specific treatment was reported as not required in 86.5\% (608) of the 703 cases. In the 29 cases where a specific treatment was recorded, it involved eye irrigation (13), oral activated charcoal (5), skin decontamination (5), topical antibiotics to the eye (4), oral fluids (2), analgesia (2), gastric lavage (1), intravenous fluid (1), oral antihistamines (1), oral antibiotics (1) or topical emollient (1), in line with the advice provided on TOXBASE. No children were admitted to intensive care, required ventilation or were reported to have significant complications or longer-term effects from the exposure. There were no deaths reported in our study group, and the national data sets on mortality are not product specific ${ }^{10}$ and so do not assist further analysis in this regard.

\section{DISCUSSION}

In contrast to the situation for drugs, there is at present no formal system for toxicovigilance for other products in the

Table 1 Gender and age group of 1123 children involved in acute, accidental exposures where a specific age was recorded

\begin{tabular}{|c|c|c|c|c|c|c|c|c|}
\hline \multirow{2}{*}{$\begin{array}{l}\text { Age } \\
\text { (years) }\end{array}$} & \multirow[b]{2}{*}{ No } & \multicolumn{2}{|c|}{ Boys exposed to pesticides } & \multicolumn{2}{|c|}{ Girls exposed to pesticides } & \multirow{2}{*}{$\begin{array}{l}\text { Gender } \\
\text { not } \\
\text { known }\end{array}$} & \multirow[b]{2}{*}{$\chi^{2}$} & \multirow[b]{2}{*}{ p Value } \\
\hline & & No $(\%)$ & Ratio (95\% Cl) & No $(\%)$ & Ratio (95\% Cl) & & & \\
\hline $0-4$ & 943 & $543(58.0)$ & $0.58(0.55-0.61)$ & $394(42.0)$ & $0.42(0.39-0.45)$ & 6 & 23.69 & 0.0001 \\
\hline $5-9$ & 147 & $72(49.7)$ & $0.50(0.42-0.58)$ & $73(50.3)$ & $0.50(0.42-0.58)$ & 2 & 0.01 & 0.9338 \\
\hline $10-12$ & 33 & $19(57.6)$ & $0.58(0.41-0.73)$ & $14(42.4)$ & $0.42(0.27-0.59)$ & 0 & 0.76 & 0.3841 \\
\hline
\end{tabular}


Table 2 Agents most frequently reported by the respondent in acute, accidental exposures in children $\leqslant 12$ years old (where frequency $\geqslant 30$ times)

\begin{tabular}{ll}
\hline Agent & No of exposures \\
\hline Permethrin & 161 \\
Malathion & 152 \\
Metaldehyde & 139 \\
Bromadiolone & 94 \\
Borax & 86 \\
Difenacoum & 60 \\
Diquat & 39 \\
Glyphosate & 39 \\
Bendiocarb & 32 \\
Phenols/Cresols* & 30 \\
\hline
\end{tabular}

*From creosote. Creosote has been banned since 2003. However, some members of the public use creosote generically to denote wood preservative, so these are probably not all creosote. This is therefore likely to be an overestimate.

UK. ${ }^{11-14}$ The importance of post-marketing surveillance has been recently emphasised in connection with adverse effects in respect of waterproofing sprays ${ }^{15}$ and toys. ${ }^{16}$

TOXBASE product entries were accessed more than 1000000 times in 2007. Since pesticide accesses are a small proportion of the total database use, intensive monitoring of the type described is possible. There was a disappointingly low response rate $(7.8 \%)$ to online use of a questionnaire and this may reflect the way in which TOXBASE is used in front-line clinical situations. Follow-up rates were far higher for telephone enquiries (53.6\%) and postal questionnaires (23.6\%). It is not possible to say whether symptoms may positively bias the return of reports, but as the children in $80.6 \%$ of cases reported were asymptomatic, this seems unlikely.

The distribution of patient age and gender reported in this study reflects many of the patterns that have been found in previous epidemiological studies of general poisoning and suggests that the data collected reflect the overall pattern of exposure. ${ }^{17-25}$ These similarities support the concept that the surveillance approach we have used is likely to reflect overall patient exposure patterns, and while it is possible that this low response rate might bias the results, these similarities make it less likely.

It is unlikely that all patients were exposed to pesticide if exposures reflect other experience in childhood poisoning where laboratory confirmation was conducted. ${ }^{26}$ Confirmation of exposure to pesticides is challenging in routine practice, as assays are not widely available. In this series, exposures to anticoagulants and organophosphates (cholinesterase inhibitors) are best suited to this approach. Thus, of 18 children exposed to anticoagulants, the results of clotting studies were abnormal in only two. No assays were reported in relation to organophosphates, but assays are clinically indicated only in patients with symptoms.

Most exposures (84.0\%) occurred in children under the age of 5 years, with children aged 2 the most frequently exposed (fig 1). These findings concur with those of previous studies on childhood poisoning. ${ }^{18-22} 25$ 27-30 Most of the exposures reported either occurred after the pesticide, usually a bait-type compound, had been applied (28.7\%) or were due to unsatisfactory storage (19.9\%). Exposures through ingestion were common (in $69.1 \%)$, with rodenticides (22.5\%), ant killers $(20.8 \%)$ and slug killers $(12.1 \%)$ being prominent.

Despite the large number of children presenting to healthcare professionals, most exposures did not produce symptoms
(80.6\% asymptomatic) and were considered of "minor" severity $(76.2 \%)$ by the healthcare professional involved. Most of the children exposed (96.4\%) either were not admitted to hospital or were discharged on the same day. No patients were reported as being admitted for more than 2 days. The cases in which an admission of 2 days was recorded followed exposure to rodenticides.

Head lice treatments accounted for $15.5 \%$ of exposures. There is potential to reduce therapeutic error through education, repackaging or improved storage. These products were either mistaken by children themselves or by carers as an oral pharmaceutical.

\section{CONCLUSIONS}

The effects of potentially toxic pesticides on health can be monitored using NPIS resources. Most suspected pesticide exposures of children resulted in no clear acute adverse health outcome and were considered of minor severity. No children were reported to have died or to have been admitted to intensive care. Nevertheless, issues such as safety of storage and care after application of bait-style products were highlighted. There would appear to be potential for reducing such exposures through health education and improved packaging and labeling.

Acknowledgements: This study was conceived by Professor DN Bateman and planned by Professor DN Bateman and Mrs Alison Good. Mr RD Adams and Mr D Lupton collected and analysed the data. Mr RD Adams drafted the manuscript and all authors contributed to the final version.

Funding: The UK Health and Safety Executive and the Pesticide Safety Directorate funded this study. The funding sponsor had no role in the design of the study other than to request a range of pesticides about which they were specifically interested in gathering exposure data. The study sponsor played no role in the collection, analysis or interpretation of data. The study sponsor also played no role in writing the report or the decision to submit the paper for publication.

\section{Competing interests: None.}

Mr Richard D Adams, Mr David Lupton, Mrs Alison M Good and Professor David Nicholas Bateman are all based at NPIS Edinburgh in the Royal Infirmary of Edinburgh, Scotland.

\section{REFERENCES}

1. Baker P, Selvey D. Malathion-induced epidemic hysteria in an elementary school. Vet Hum Toxicol 1992;34:156-60.

2. Bowler RM, Mergler D, Huel G, et al. Aftermath of a chemical spill: psychological and physiological sequelae. Neurotoxicology 1994;15:723-9.

3. Gupta K, Perharic L, Volans GN, et al. Apparent poisoning by wood preservatives: an attributional syndrome. J Psychosom Res 1997;43:391-8.

4. Kahn E, Jackson RJ, Lyman DO, et al. A crisis of community anxiety and mistrust: the Medfly eradication project in Santa Clara County, California, 1981-2. Am J Public Health 1990;80:1301-4.

5. Bateman DN, Good AM, Kelly CA, et al. Web based information on clinical toxicology for the United Kingdom: uptake and utilization of TOXBASE in 2000. Br J Clin Pharmacol 2002;54:3-9

6. National Poisons Information Service. Annual Report 2007/2008. London: Health Protection Agency, 2008. http://www.hpa.org.uk/webw/HPAwebgHPAwebStandard/ HPAweb C/1221379219767?p=1158934607583 (accessed 26 Mar 2009).

7. Bateman DN, Good AM. Five years of poisons information on the internet, the UK experience of TOXBASE. Emerg Med J 2006;23:614-7.

8. Leverton K, Cox V, Battershill J, et al. Hospital admission for accidental pesticide poisoning among adults of working age in England, 1998-2003. Clin Toxicol (Phila) 2007:45:594-7.

9. Persson HE, Sjoberg GK, Haines JA, et al. Poisoning severity score: grading of acute poisoning. J Toxicol Clin Toxicol 1998;36:205-13.

10. Office for National Statistics. Mortality statistics: injury and poisoning (series DH4). http://www.statistics.gov.uk/STATBASE/Product.asp?vlnk=621 (accessed 30 Mar 2009).

11. Inman WH. Postmarketing surveillance of adverse drug reactions in general practice. I: search for new methods. Br Med J (Clin Res Ed) 1981;282:1131-2.

12. Mann RD. An instructive example of a long-latency adverse drug reactionsclerosing peritonitis due to practolol. Pharmacoepidemiol Drug Saf 2007;16:1211-6.

13. Morrison-Griffiths S, Walley TJ, Park BK, et al. Reporting of adverse drug reactions by nurses. Lancet 2003;361:1347-8. 
14. Richardson J, Holdcroft A. Results of forty years Yellow Card reporting for commonly used perioperative analgesic drugs. Pharmacoepidemiol Drug Saf 2007; 16:687-94.

15. Vernez D, Bruzzi R, Kupferschmidt $H$, et al. Acute respiratory syndrome after inhalation of waterproofing sprays: a posteriori exposure-response assessment in 102 cases. J Occup Environ Hyg 2006;3:250-61.

16. Gunja N, Doyle E, Carpenter K, et al. $\gamma$-Hydroxybutyrate poisoning from toy beads. Med J Aust 2008;188:54-5.

17. Bronstein AC, Spyker DA, Cantilena LR Jr, et al. 2006 annual report of the American Association of Poisons Control Centers' National Poison Data System (NPDS). ClinToxicol (Phila) 2007;45:815-917.

18. Hincal F, Hincal AA, Muftu Y, et al. Epidemiological aspects of childhood poisonings in Ankara: a 10-year survey. Hum Toxicol 1987;6:147-52

19. Hsu R, Coles EC, Routledge PA. Childhood poisoning in Wales: experience of the Welsh National Poisons Unit (1984). Hum Toxicol 1986:5:373-6.

20. Meyer S, Eddleston M, Bailey B, et al. Unintentional household poisoning in children. Klin Padiatr 2007;219:254-70.

21. Campbell D, Oates RK. Childhood poisoning: a changing profile with scope for prevention. Med J Aust 1992;156:238-40.
22. Lawson GR, Craft AW, Jackson RH. Changing pattern of poisoning in children in Newcastle 1974-81. Br Med J (Clin Res Ed) 1983;287:15-7.

23. Pearn J, Nixon J, Ansford A, et al. Accidental poisoning in childhood: five year urban population study with 15 year analysis of fatality. Br Med J (Clin Res Ed) 1984;288:44-6.

24. Petridou E, Polychronopoulou A, Kouri N, et al. Unintentional childhood poisoning in Athens: a mirror of consumerism? J Toxicol Clin Toxicol 1997;35:669-75.

25. Reith DM, Hockey R, Pitt WR. Childhood poisoning in Queensland: an analysis of presentation and admission rates. J Paediatr Child Health 2001;37:446-50.

26. Hwang CF, Foot CL, Eddie G, et al. The utility of the history and clinical signs of poisoning in childhood: a prospective study. Ther Drug Monit 2003;25:728-34.

27. Tibballs J, McArdle EJ, Brown TC. Drug overdose in children. Aust Paediatr J 1985;21:7-11.

28. Woolf AD, Lovejoy FH Jr. Epidemiology of drug overdose in children. Drug Saf 1993;9:291-308.

29. Meredith TJ. Epidemiology of poisoning. Pharmacol Ther 1993:59:251-6

30. Rodriguez JG, Sattin RW. Epidemiology of childhood poisonings leading to hospitalization in the United States, 1979-1983. Am J Prev Med 1987;3:164-70.

\section{Archivist}

\section{Hyperinsulinism-hyperammonaemia syndrome}

The hyperinsulinism-hyperammonaemia syndrome (HHS) was reported in a series of eight patients in 1988. Since then several series of up to 14 patients have been reported. The cause is an activating missense mutation in the GLUD1 gene at chromosome 10q23.3 that encodes glutamate dehydrogenase (GDH). The mutations occur either de novo or with dominant inheritance. The activity of GDH is enhanced by reduction of the inhibitory effect on GDH of guanosine triphosphate (GTP) and adenosine triphosphate (ATP). In HHS the biochemical disturbance affects the pancreas, the liver, and possibly the brain. The main clinical features are recurrent hypoglycaemia (it is a cause of leucine-induced hypoglycaemia) beginning in early infancy, and mild to moderate hyperammonaemia without lethargy, headaches or acute hyperammonaemic crises. Now the neurological aspects of the syndrome have been emphasised in a report of 22 patients from 17 families from centres in France, Italy and Belgium (Nadia BahiBuisson and colleagues. Developmental Medicine and Child Neurology 2008;50:945-9; see also Commentary, ibid: 888). The series consisted of 12 males and 10 females aged 18 months to 40 years, all with HHS proved genetically or biochemically. Learning disability was present in 17 patients and 14 had childhood-onset epilepsy, often with atypical absences. Less frequent seizure types included focal motor seizures and generalised tonic-clonic seizures. Eleven patients responded well to anticonvulsant drugs. Two patients had pyramidal tract involvement and one had generalised dystonia.

Four patients had signs of hypoglycaemia within 3 days of birth, but the median age at recognition of hypoglycaemia was 5 months. Seventeen patients had hypoglycaemic seizures. The hypoglycaemia was usually well controlled with diazoxide or a leucine-restricted diet or cornstarch, but one patient needed partial pancreatectomy. Mean ammonia concentrations varied from 117 to $128 \mu \mathrm{mol} / \mathrm{l}$ in different groups, but did not differ significantly between patients with or without epilepsy or learning disability. GDH overactivity affects the pancreas (hypoglycaemia), the liver (hyperammonaemia) and the brain. Whether the neurological problems seen in HHS are a consequence of hypoglycaemia or hyperammonaemia, or reflect brain GDH activity remains uncertain, but there is a suggestion from this series that mutations in the GTP binding site of GDH might predispose to epilepsy. Brain GDH activity could be important in regulating neurotransmitters such as GABA. 